\title{
BULLETIN
}

\section{Characters of variation of L URR during the earthquake sequence of Xinjiang}

\author{
WANG Hait a ${ }^{1,3,4}$, PENG Keyin ${ }^{2,3}$, ZHANG Yongxian ${ }^{2,3}$, \\ WANG Yucang ${ }^{3,4}$ and YIN Xiangchu ${ }^{2,4}$
}

1. Xinjiang Seismological Bureau, Urumqi 830011, China; 2. Center for Analysis and Prediction, State Seismological Bureau, Beijing 100036, China; 3. Institute of Geophysics, State Seismological Bureau, Beijing 100081, China; 4. Laboratory of Nonlinear Mechanics, Institute of Mechanics, Chinese Academy of Sciences, Beijing 100080 , China

\begin{abstract}
The theory of the loading/ unloading response ratio (LURR) was applied to the Jiashi earthquake sequence which occurred at the beginning of 1997 in Xinjiang, and found that, before the earthr quakes with relatively high magnitudes in the sequence, the ratio showed anomalies of high values. That is to say, the LURR theory can be applied to the short-term earthquake prediction in some cases , especially in the early period after a strong earthquake, such as the forecasts for some strong earthquakes in the Jiashi sequence.
\end{abstract}

Key words : Jiashi earthquake sequence, theory of loading/ unloading response ratio (L URR), earthquake sequence.

AFTER the occurrence of a strong earthquake, the immediate requirement is to make a judgment as soon as possible if there are probabilities of the occurrence of another earthquake with a larger or the same magnitude, and furthermore, if the sequence is of a mainshock-aftershock type, i. e. if only earthquakes with smaller magnitude than the mainshock occur.

The Jiashi sequence began with a $M_{\mathrm{s}} 6.4$ earthquake at 09:47, $21 \mathrm{Jan}$. , 1997 (located at 39.6N , 76.9E), and till 31 May, 1997, 7 earthquakes with magnitudes $\geq 6$ and in total 5480 earthquakes with magnitudes $M_{\mathrm{L}} \geq 1.0$ occurred. Among them, the strongest one is the $M_{\mathrm{s}} 6.6$ earthquake on 11 April , 1997. It is rare and noticeable in geoscience studies that so many strong earthquakes occurred in such a short period in the same region.

The sequence was too complicated for the usual methods to analyze. Using the records from the Kashi Seismological Observation, Xinjiang, we traced the variation of LURR during the process of the swarm, trying to apply the theory of the LURR to the tendency judgment after large earthquakes. We found that the LURR had shown high value anomalies before the relatively large earthquakes in the sequence. Successful forecasts were made before some of these large ones.

\section{Methods}

The theory of LURR ${ }^{[1-4]}$ introduced a new parameter, LURR $(Y)$, which gives the instability of a nonlinear system. Its definition is

$$
Y=\frac{X_{+}}{X_{-}},
$$

where $X_{+}$and $X$. represent the response rate of the system in the loading and the unloading period, respectively. When the system is in a stable state, the values of the loading/ unloading re- 
sponse rate are approximately equal, and thus $Y$ is about 1 ; when the system gets closer to the unstable state, the loading response rate becomes bigger than the unloading one, and thus the $Y$ value increases; when the system is in an unstable state, $Y$ will tend to infinity.

We take the stress caused by the action of tide induced forces by the sun and the moon to the lithosphere as the source for loading/ unloading, and the geophysical variables, such as crust deformation, gravity, underground water level, which can show the process that the system becomes unstable, as the response. Up to now, the LURR with the energy released by the earthquakes in the studied region as the response has been sufficiently studied and applied.

The algorithm to calculate the LURR is outlined below:

$$
Y=\frac{\left(\sum^{n_{+}} E_{i}^{m}\right)_{+}}{\left(\sum E_{i}^{m}\right) .}
$$

where" +" and" - " represent loading and unloading respectively, the subscript $i$ gives the sequence number, and $m$ can be any of $0,1 / 3,1 / 2,2 / 3,1$, etc. Here we use $m=1 / 2$ to calculate the LURR.

As a new method for earthquake prediction, the theory of the LURR has been tested by different kinds of earthquake data. Some satisfying results were obtained after it was put into practice $^{[2,4]}$.

\section{Analysis on the background anomaly bef ore the occurrence of the sequence}

To calculate the LURR values in the period from the year 1990 to the occurrence time of the sequence, we used the earthquake data from a $2^{\circ} \times 2^{\circ}$ region neighboring the epicenters, and took 1 year as the length of time windows and 2 months. as the sliding step length (figure 1).

From fig. 1 , we can see that the $Y$ value keeps a low level from 1990 to 11 Nov., 1994. From the end of 1994 on , $Y$ shows high value anomalies for about 1 year. In March 1996 ,

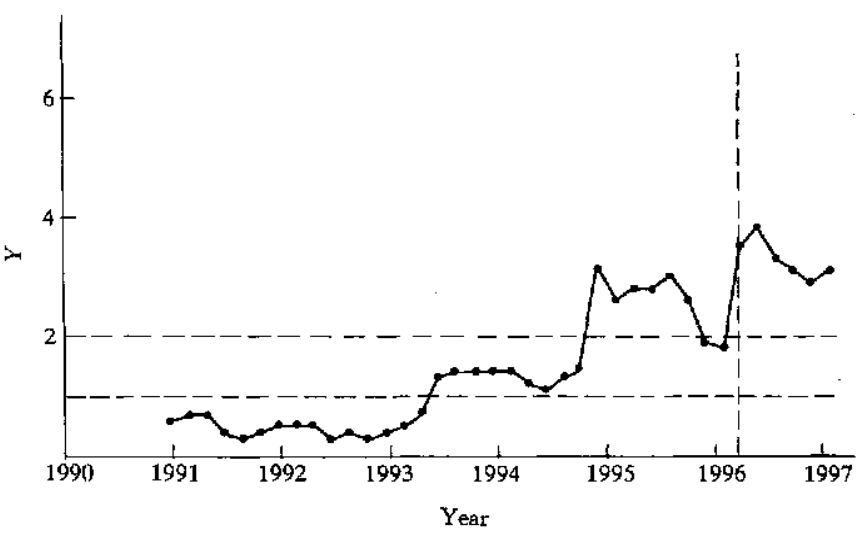
an $M_{\mathrm{s}} 6.9$ earthquake occurred in Atux, $40 \mathrm{~km}$ from Jiashi. After the Fig. 1. Variation of the $Y$ value in the epicentral region before the Jiashi earthquake, the $Y$ value keeps a high swarm.

level. The shape of variation of the $Y$ value here is similar to that for the $M_{\mathrm{s}} 6.1$ and $M_{\mathrm{S}} 6.2$ earthquakes in Beibu Gulf. That is to say, the high value anomalies of $Y$ to some extent show that the system for the earthquake preparation or the earth blocks are still in an unstable state or more unstable, and imply that another one or more earthquakes would occur. In a word, the anomalies 


\section{BULLETIN}

of the LURR are quite distinguished in this region before the earthquake sequence.

\section{Tracing the $\mathrm{Y}$ value during the sequence}

The activity in the decay process of this earthquake sequence is quite changeable from its beginning. Although the work tracing the sequence found some anomalies before a part of the relatively large earthquakes in the sequence by using the usual methods, such as $h$-value, $b$-value, seismic wave parameters, etc., the analysis on the whole process of the sequence is still far from satisf ying.

To study the features of the LURR' $s$ variation in the process of the sequence systematically, in real time, we calculated the $Y$ value using a sliding time window with a $\lambda$ length of 5 days and a step of 2 days. The variation of the $Y$ values with time is shown in figure 2.

From fig. 2, after the $M_{\mathrm{s}} 6.4$ earthquake on 21 January, the $Y$ values formed several peaks in a time interval of 4 or 5 months, not as the usual mainshock-aftershock type se- solid line represents more than one earthquake in the same day. The scale of quence which has $Y$ values decreas- the vertical axis gives the values of LURR and the magnitudes of the earthing rapidly to 1 . The seismicity in quakes.

this period is that several strong earthquakes with the maximum magnitude of 6.4 occurred and formed the Jiashi strong earthquake swarm. The seismicity patterns concord with the features of the $Y$ values.

There are 4 peaks with $Y>2$, correspondingly, 1 or more earthquakes with $M_{\mathrm{s}}>5$ occurred after or in each peak and almost no event in the non-peak periods. No earthquake with $M_{\mathrm{s}}>5$ oc- $^{-}$ curred during the other small peaks.

\section{Conclusion and discussion}

The above analysis shows that the loading/ unloading response ratio gives effective information of anomaly in the process of the Jiashi earthquake sequence. The high values of the LURR usually occur several days before big earthquakes. That is to say, after a strong earthquake, there is high risk of another strong earthquake in a few days if the peaks of the LURR value reappeared.

Recently, the internationnal seismological field discussed quite lot of topics on the earthquake prediction. No breakthrough has made in the research on the earthquake prediction, especially for short-term or immediate prediction, although it has been studied for several decades. Many seismologists feel pessimistic about it and believe that it is difficult to make a short-term prediction with the precision of several days in the present stage. The Chinese seismologists have made some 
achievements in this field in the last several decades. The study on the variation of the LURR in this note can be one of them.

Ackno wledgement This work was supported by the Ninth Five- Year National Key Projects, the National Natural Science Foundation of China (Grant No. 19702060) and the Laboratory of Nonlinear Mechanics, Institute of Mechanics, CAS.

\title{
References
}

1 Yin, X. C. , Yin, C. , The precursor of instability for nonlinear systems and its applications to earthquake prediction, Science in China, Ser. B , 1991(8) : 997.

2 Yin, X. C. , Yin, C. , A new approach to earthquake prediction, Russia's Nature (in Russian), 1993(1): 21.

3 Yin, X. C. , Yin, C. , The precursor of instability for nonlinear systems and its application to earthquake prediction $\longrightarrow$ the load-unload response ratio theory, Nonlinear Dynamics and Predictability of Geophysical Phenomena (eds. Newman, W. L. , Gabielov, A. M. ), AGU, Monograph, 1993, 83: 55.

4 Yin, X. C. , Chen, X. Y. , A new approach to earthquake prediction the load/ unload response ratio (LURR) theory, PA GEOPH, 1995(3-4) : 701.

\section{Discovery of eclogite at northern margin of Qaidam Basin, NW China}

\section{YANG J ings ui, XU Zhiqin, LI Haibing, WU Cailai, CUI J unwen, ZHANG Jianxin \& CHEN Wen}

Institute of Geology, Chinese Academy of Geological Sciences, Beijing 100037 , China

\begin{abstract}
Eclogite was first discovered at the northern margin of the Qaidam Basin in this study. It occurs as pods in the gneiss sequence of Middle to Upper Proterozoic age and is mainly composed of garnet, omphacite, phengite and rutile. The garnets contain $44 \%-62 \%$ of almandine, $15 \%-33 \%$ of grossular and $12 \%-30 \%$ of pyrope molecules, and the omphacites contain $40 \%-46 \%$ of jadeite. Applying garnet-clinopyroxene thermometry and jadeite geobarometry, the peak conditions of eclogite facies metamorphism occurred at about $(722 \pm 123){ }^{\circ} \mathrm{C}$ and at the pressure of up to c. $22 \times 10^{8} \mathrm{~Pa}$.
\end{abstract}

Key words : eclogite, high- pressure metamorphism, Da Qaidam, Qinghai- Xizang Plateau.

THE coecite-bearing eclogite and ultra-high pressure metamorphism in the Dabie and Sulu areas in East China have been attracting great attention of the geoscientists in the world since they were recognized in $1987^{[1,2]}$. Eclogite and high-pressure metamorphism have also been reported from the Altyn Tagh and Tianshan Mountains ${ }^{[3,4]}$, NW China in recent years. During the field season of Sino- French collaboration of 1996 we found that eclogites occur at the northern margin of the Qaidam Basin. All these discoveries make us reconsider the tectonic framework of NW China as well as of East China. 